\title{
Lengthening of the first metatarsal bone
}

\section{A case of congenital shortening}

\author{
Santiago Amillo, Jorge Gil-Albarova and Tomas Pampliega
}

A 14-year-old boy had a congenital shortening of the first right metatarsal bone, with overloading of the central metatarsals and medial deviation of the second toe. A percutaneous osteotomy and slow distraction by an external fixator for 10 weeks

lengthened the bone from $32 \mathrm{~mm}$ to $60 \mathrm{~mm}$. After the distraction, a bone graft was performed, and tenotomies and a capsulotomy corrected a threatening subluxation. Consolidation of the lengthening focus required 16 weeks.

Department of Orthopedics, University Clinic of Navarra, Pio XII st. (s/n), E-31008 Pamplona, Spain

Tel +34-948 255900 and 255400. Submitted 90-06-11. Accepted 90-11-30.

\section{Case report}

A 14-year-old boy complained of pain in his right forefoot upon weight bearing that forced him to limp. He had a congenital shortening of the first metatarsal with varus deviation. Further, he had right hypoplasia of the first cuniform bone, the first metatarsus of the first metatarsophalangeal joint (Figure 1). He had no other malformations, nor any personal or family antecedents of interest.

Lengthening of the first metatarsal with a monolateral external fixator (Orthofix ${ }^{\mathbb{B}}$ ) by diaphyseal percutaneous osteotomy was performed under fluoroscopy applying a $2-\mathrm{mm}$ distraction in the initial operation and deferring the start of lengthening by 1 week. The osteotomy was performed with a chisel, which was introduced through a $0.5-\mathrm{cm}$ cutaneous incision in the third half of the diaphysis. The pins were placed in the intersecting line of the saggital and horizontal planes. Due to a lack of space, the most proximal pin was placed in the second metatarsus and the first cuniform, while the other proximal pin was fixed in the first and second metatarsals. The distraction was increased by $0.5 \mathrm{~mm}$ every 12 hours for 3 weeks, and after that by $0.25 \mathrm{~mm}$ every 12 hours for 3 weeks. Clinical and radiographic verifications were undertaken at 2 -week intervals.
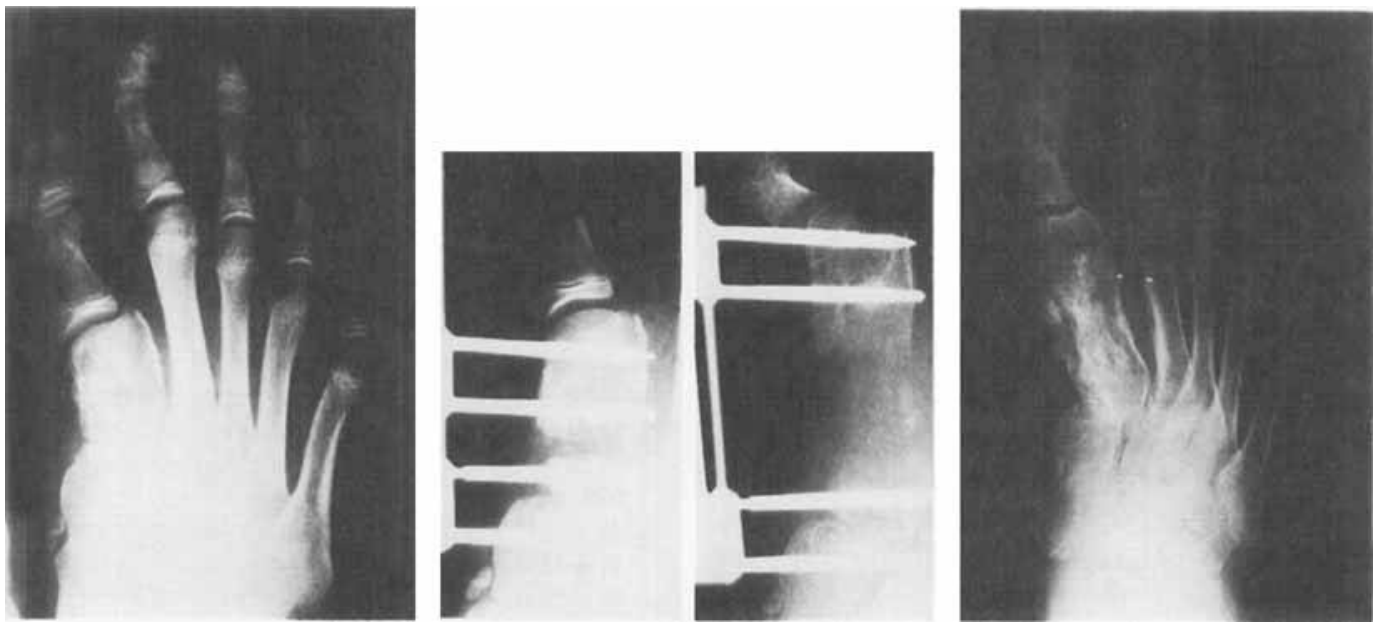

Figure 1. A 14-year-old boy with a congenital shortening of the first metatarsus with an anomalous articulation between the first and second cunei and a discrete medialization of the first toe. Cortical enlargement of the second metatarsus. 
At 10 weeks, we performed a Z-lengthening of the flexor tendon of the first toe, a tenotomy of the abductor muscle, and a capsulotomy of the metatarsophalangeal joint to correct the subluxation, which had become more obvious during the lengthening. An autologous cancellous bone graft, obtained from the distal tibia metaphysis, was performed to ensure early consolidation of the lengthened area.

During his last visit 1 year later, the boy stated that he was leading a normal life and that the pain he had complained about had disappeared. He had $10^{\circ}$ of flexion and $40^{\circ}$ of extension. The lengthened segment had consolidated, and the metatarsal length had increased from $32 \mathrm{~mm}$ to $60 \mathrm{~mm}$.

\section{Discussion}

Different methods and indications for bone lengthening of the hand (Kessler et al. 1977 and 1979, Lundborg et al. 1987) and foot (Nogarin et al. 1988, Wakisaka et al. 1988) are described in the literature. Among these methods, there are differences in the type of external fixator that has been employed and in the use of a bone graft to gain consolidation of the lengthened segment (Lundborg et al. 1987, Nogarin et al. 1988, Wakisaka et al. 1988).

We feel that the monolateral fixator has an adequate application for the lengthening of tubular bones, and that there is no reason for its use to be limited to the long limb bones.

In the case presented here, we performed a percutaneous corticotomy (Monticelli et al. 1983, Peltonen et al. 1988), trying to avoid damage to the periosteum and the adjacent soft parts to preserve the vascularization of the fixus according to Ilizarov's concept (Ilizarov 1963, Ilizarov and Soibelman 1969). The closed osteotomy (as we prefer to call it) allows the formation of a better quality callus when compared with the open osteotomies, which has been shown experimentally in our department (Arrien 1987, De Pablos and Canadell 1987). In addition, we have followed the basic concept of De Bastiani as regards "callotasis" (Alho et al. 1982, De Bastiani et al. 1987, Kojimoto et al. 1988, Nogarin et al. 1988, Peltonen et al. 1988, Wakisaka et al. 1988).
We concluded from the evolution of our case that tenotomies or tendon lengthenings may be necessary to maintain correct functioning of the joints near the lengthening focus depending on the extent of lengthening. This procedure accords with that of Wakisaka et al. (1988), although they performed tenotomies during the initial surgery.

Upon completion of distraction, a graft facilitates callus ossification and reduces the length of time that the fixator needs to be left in place (Lundborg et al. 1987).

\section{References}

Alho A, Bang G, Karaharju E, Armond I. Filling of a bone defect during experimental osteotaxis distraction. Acta Orthop Scand 1982; 53 (1): 29-34.

Arrien A. Estudio comparativo de la osteotomia a cielo abierto y percutanea en la elongacion de las extremidades. Thesis, Universidad de Navarra, Pamplona, Espana 1987.

De Bastiani G, Aldegheri R, Renzi Brivio L, Trivella G. Limb lengthening by callus distraction (callotasis). $J$ Pediatr Orthop 1987; 7 (2): 129-34.

De Pablos J, Canadell J. Elongacion de miembros inferiores. Experiencia en la Clinica Universitaria de Navarra. Rev Med Univ Navarra 1987; 31 (1): 43-52.

llizarov $G$ A. Lower limb lengthening experience by Ilizarov's apparatus. 13th scientific regional celebrative conference for 300th anniversary of Kurgan town 1963: 319-29.

Ilizarov G A, Soibelman L M. Clinical and experimental data on bloodless lengthening of lower extremities. Eksp Khir Anesteziol 1969; 14 (4): 27-32.

Kessler I, Baruch A, Hecht O. Experience with distraction lengthening of digital rays in congenital anomalies. $J$ Hand Surg (Am) 1977; 2 (5): 394-401.

Kessler I, Hecht O, Baruch A. Distraction lengthening of digital rays in the management of the injured hand. $J$ Bone Joint Surg (Am) 1979; 61 (1): 83-7.

Lundborg G, Sollerman C. A case of phalangeal lengthening. Acta Orthop Scand 1987; 58 (4): 423-5.

Monticelli G, Spinelli R. Leg lengthening by closed metaphyseal corticotomy. Ital $J$ Orthop Traumatol 1983; 9 (2): 139-50.

Nogarin L, Magnan B, Bragantini A, Molinaroli F. The surgical correction of metatarsal dysmetria. Ital $J$ Orthop Traumatol 1988; 14 (1): 77-80.

Peltonen J, Karaharju E, Aalto K, Alitalo I, Hietaniemi K. Leg lengthening by osteotomy and gradual distraction: an experimental study. $J$ Pediatr Orthop 1988; 8 (5): 509-12.

Wakisaka T, Yasui N, Kojimoto H, Takasu M, Shimomura Y. A case of short metatarsal bones lengthened by callus distraction. Acta Orthop Scand 1988; 59 (2): 1946. 